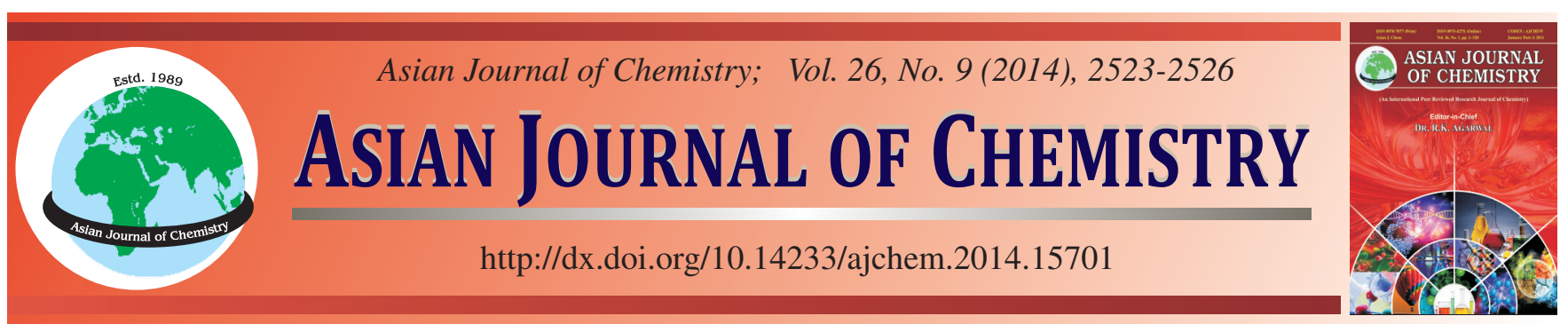

\title{
A Non-Noble Metal Electrocatalyst for Oxygen Reduction Reaction Using Egg-White Protein as Nitrogen Source
}

\author{
Ping Liu ${ }^{1}$, Changguo Chen ${ }^{1, *}$, Chaozhong Guo ${ }^{1,2}$, Mo Du $^{1}$, Huijuan Wu ${ }^{1}$ and Wei Yin ${ }^{1}$
}

${ }^{1}$ College of Chemistry and Chemical Engineering, Chongqing University, Chongqing 400044, P.R. China

${ }^{2}$ Research Institute for New Material Technology, Chongqing University of Arts and Sciences, Yongchuan 402160, P.R. China

*Corresponding author: Tel: +86 23 65111357; E-mail: cgchen@ cqu.edu.cn

Egg-white protein as one of native proteins contains abundant nitrogen and can be obtained with abundant and inexpensive. Herein, we reported that a novel non-noble metal electrocatalyst for oxygen reduction reaction (ORR) was fabricated by thermal treatment of the precursor (including egg-white protein as the direct nitrogen source, $\mathrm{FeCl}_{3} \cdot 6 \mathrm{H}_{2} \mathrm{O}$ as the metal source and pretreated carbon black as the support) under an inert atmosphere. The voltammetric methods were used to evaluate the oxygen reduction reaction catalytic activity, stability and methanol-tolerant performance of the catalyst. The structural property of the catalyst was also investigated by X-ray diffraction. The results show that the catalyst achieved at $800{ }^{\circ} \mathrm{C}$ has good activity, high methanol-tolerant and long-term stability. The metal content in this catalyst plays a critical role in improving the oxygen reduction reaction activity. An important finding is the Fe and its oxides are not the catalytically active sites for the oxygen reduction reaction, and their existence may facilitate the formation of the oxygen reduction reaction-active sites only. Besides, the activated amorphous-carbon is also found.

Keywords: Oxygen reduction, Electrocatalyst, Egg-white protein, Nitrogen source.

\section{INTRODUCTION}

Fuel cells have become the most promising clean energyconverting devices owing to their excellent properties of high energy conversion efficiency, abundant fuel sources and low emissions ${ }^{1}$. The platinum and its alloys dispersed on the carbons are considered as the most effective electrocatalyt for the oxygen reduction reaction until now ${ }^{2}$. However, their high cost and scarcity have limited the rapid development and commercial application of full cell technologies. Especially, the methanol molecule can cross over the proton exchange membrane and oxidize on the Pt-based catalysts, resulting in losing the catalytic activity ${ }^{3}$. The further produced carbon monoxide will also poison the Pt catalyst, which makes its active sites inactivation. Thus, it is indispensable to design the novel nonprecious metal catalysts (NPMCs) for replacing the Pt catalyst partially and completely.

Many approaches to enhance the oxygen reduction reaction activity and stability of the non-precious metal catalysts have been explored. Remarkably, the non-precious metal catalysts from heat-treatment of metal-Nx macrocycles, such as $\mathrm{Fe}$ - and Co-macrocycles, have attracted much attention due to their reasonable catalytic activity and high selectivity towards oxygen reduction reaction ${ }^{4-7}$. In addition, the good methanol-tolerant performance of the non-precious metal catalysts will play an important role in direct methanol fuel cells (DMFCs) ${ }^{8}$. Recently, several studies have reported that the non-precious metal catalysts were prepared by using hemoglobin as the precursor and their oxygen reduction reaction electrocatalytic activity could compare favorably with the commercial Pt/C catalyst ${ }^{9-13}$. A certain protein i.e., hemin, was also used for preparing the Pt-free catalyst upon the pyrolysis process ${ }^{14-16}$. These results indicate that the non-precious metal catalysts prepared with proteins have superior academic value and practical significance, although there is no systematic study on heat-treated proteins until now.

Therefore, we design a non-noble metal electrocatalyst $(\mathrm{FeEw} / \mathrm{C})$ using the egg-white $(\mathrm{Ew})$ protein as the nitrogen source. The oxygen reduction reaction catalytic activity, stability and methanol-tolerant property of the electrocatalyst have been checked carefully. Our results have indicated that the FeEw/C catalyst is a promising substitute for the $\mathrm{Pt} / \mathrm{C}$.

\section{EXPERIMENTAL}

Egg-white protein (Ew) was obtained from Food Testing Center of Chongqing Bureau of Quality and Technology Supervision, China. Vulcan XC-72R carbon black (VCB) was supplied by American Cabot Company and pretreated in the $5 \mathrm{M} \mathrm{HNO}_{3}$ solution at $80{ }^{\circ} \mathrm{C}$ for $12 \mathrm{~h}$. All other chemicals were of reagent grade. 
Catalysts preparation: Assuring that the atomic ratio of Fe to $\mathrm{N}$ is $1: 6, \mathrm{FeCl}_{3} \cdot 6 \mathrm{H}_{2} \mathrm{O}$, egg white protein and $\mathrm{VCB}$ were well mixed with $50 \mathrm{~mL}$ deionized water. The obtained suspension was ultrasonically treated for $0.5 \mathrm{~h}$ at room temperature, dried at $80{ }^{\circ} \mathrm{C}$ for $12 \mathrm{~h}$ and then grounded in an agate mortar for $15 \mathrm{~min}$ to obtain the homogeneous precursor. After that, the precursor $(100 \mathrm{mg})$ was further pyrolyzed at $800{ }^{\circ} \mathrm{C}$ for 2 $h$ in a tube furnace under the flowing $\mathrm{N}_{2}$ atmosphere with a rate of $0.5 \mathrm{~L} / \mathrm{min}$ and cooled down to room temperature naturally. For convenience, the sample achieved at $800^{\circ} \mathrm{C}$ was labeled as FeEw/C (800). Based on the same conditions, the binary pre-cursors containing $\mathrm{Fe} / \mathrm{C}, \mathrm{FeEw}$ and $\mathrm{Ew} / \mathrm{C}$ were prepared. After heat-treated at $800{ }^{\circ} \mathrm{C}$, these samples were labeled as Fe/C (800), FeEw (800) and Ew/C (800), respectively.

Electrochemical measurements: The electrocatalytic activity toward oxygen reduction reaction and long-term stability for the prepared catalysts were evaluated by linear sweeping voltammetry (LSV) and their tolerance to methanol was also studied by cyclic voltammetry (CV). Electrochemical measurements were carried out on a CHI 660A electrochemical workstation (CH Instrument, USA) coupled with a traditional threeelectrode system, consisting of a catalytic thin-film working electrode, a ring-shaped Pt wire counter electrode and a SCE reference electrode. The working electrode was prepared as follows: $5 \mathrm{mg}$ of the catalysts sample, $25 \mu \mathrm{L}$ diluted Nafion solution ( 0.5 wt $\%$, with isopropyl alcohol as solvent) and $25 \mu \mathrm{L}$ deionized water were mixed under ultrasonication for $0.5 \mathrm{~h}$ to form a catalyst ink. $10 \mu \mathrm{L}$ of the catalyst ink was dropped on a glassy carbon (GC) disk electrode $(\Phi=5 \mathrm{~mm})$ by a pipettor and was naturally dried at room temperature. The LSV tests were performed from 0.9 to $-0.2 \mathrm{~V}$ in oxygen- or nitrogensaturated $0.5 \mathrm{M} \mathrm{H}_{2} \mathrm{SO}_{4}$ solution at $5 \mathrm{mV} / \mathrm{s}$. The $\mathrm{CV}$ tests for methanol-tolerant performance were carried out in oxygensaturated $0.5 \mathrm{M} \mathrm{H}_{2} \mathrm{SO}_{4}$ solution containing $1.0 \mathrm{M}$ methanol before and after completing 500 cyclic sweeping in nitrogensaturated $0.5 \mathrm{M} \mathrm{H}_{2} \mathrm{SO}_{4}$ solution at $50 \mathrm{mV} / \mathrm{s}$.

Catalysts characterization: The structural properties of the catalysts were analyzed by the X-ray diffraction (XRD) using Shimadzu XRD-6000 (Japan) X-ray diffractometer with $\mathrm{CuK}_{\alpha}$ radiation $(\lambda=1.54178 \AA)$ at the scan rate of $4 \% \mathrm{~min}$. TG/DTA measurement of the FeEw/C catalyst precursor was carried out on a Shimadzu differential thermal analyzer (DTG$60 \mathrm{H}$, Japan) under nitrogen flow. The TG/DTA measurements were recorded from ambient temperature to $900^{\circ} \mathrm{C}$ with a ramp rate of $10^{\circ} \mathrm{C} / \mathrm{min}$.

\section{RESULTS AND DISCUSSION}

TGA/DTA curves of FeEw/C precursor: Fig. 1 showed the TG/DTA curves of FeEw/C precursor. The TGA curves of the FeEw/C precursor show three changes. The first wave starts from room temperature to $159^{\circ} \mathrm{C}$. A weight loss of $13.4 \%$ can be assigned to the elimination of adsorbed water. The second wave starts at $159{ }^{\circ} \mathrm{C}$ and then reaches a plateau near $480{ }^{\circ} \mathrm{C}$, which weigh losses of $25.3 \%$ resulting from the crystallization water in $\mathrm{FeCl}_{3} \cdot 6 \mathrm{H}_{2} \mathrm{O}$ and decomposition of egg white protein at $300{ }^{\circ} \mathrm{C}$. The third wave starts at $480{ }^{\circ} \mathrm{C}$ and has a weight loss of $15.46 \%$, which is mainly ascribed to the high heat-treatment temperature. Anhydrous $\mathrm{FeCl}_{3}$ loses the

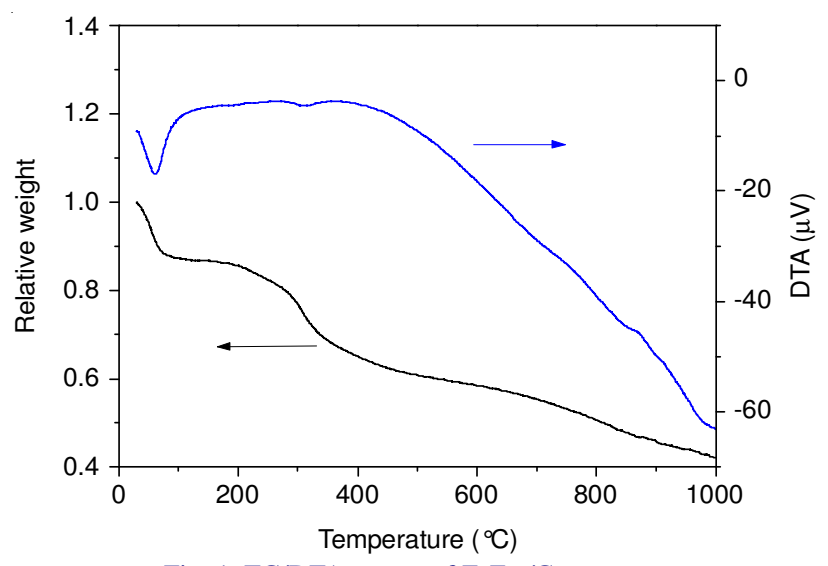

Fig. 1. TG/DTA curves of FeEw/C precursor

$\mathrm{Cl}$ element by pyrolysis, which is consistent with the subsequent XRD pattern of the FeEw/C (800). The phase containing $\mathrm{Cl}$ element consistent was not detected in the XRD pattern. Moreover, the weight of loss also include $\mathrm{C}$ element, which is accompanied by the reduction of metal $\mathrm{Fe}$. As a result, the product in the heat treatment above $480{ }^{\circ} \mathrm{C}$ has oxygen reduction reaction activity.

XRD patterns of the catalysts: Fig. 2 shows the XRD patterns of Fe/C (800), Ew/C (800), FeEw (800) and FeEw/C (800). In Ew/C (800), diffraction peaks were observed for amorphous carbon structure at the curve (d). In Fe/C(800) and FeEw(800), except for the amorphous carbon peaks can be observed, other diffraction peaks, which were assigned to the $\mathrm{Fe}_{2} \mathrm{O}_{3}$ and $\mathrm{Fe}_{3} \mathrm{O}_{4}$, also appeared at the curve (a) and (b). It can be found that the Fe/C (800) and FeEw (800) do not show an enhancing effect on the catalytic activity, indicating the presence of iron oxides is unuseful to improve the catalytic activity. Besides, in addition of the characteristic peaks of graphite and three weak peaks of iron oxides, the FeEw/C(800) also presents the formation of metal $\mathrm{Fe}$, which could promote its catalytic activity to a certain degree.

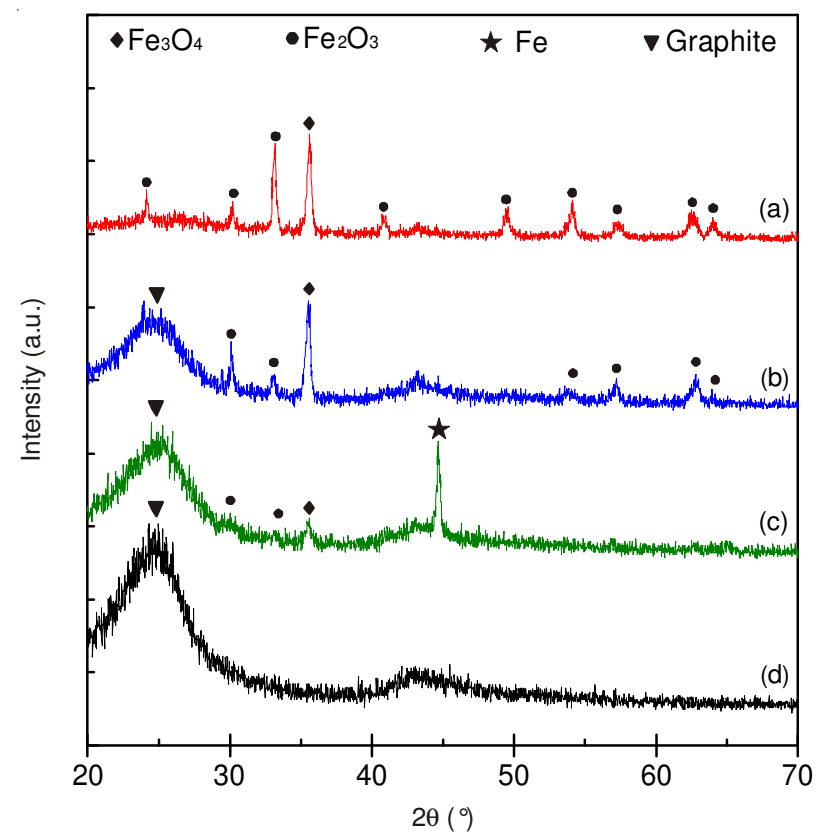

Fig. 2. XRD patterns of the oxygen reduction reaction catalysts (a) FeEw(800), (b) Fe/C(800), (c) FeEw/C(800) and (d) Ew/C(800) 
To further determine the role of metal $\mathrm{Fe}$ of $\mathrm{FeEw} / \mathrm{C}(800)$, the $\mathrm{FeEw} / \mathrm{C}(800)$ was boiled for $1 \mathrm{~h}$ in $0.5 \mathrm{M} \mathrm{H}_{2} \mathrm{SO}_{4}$ solution to remove $\mathrm{Fe}$. It was observed that the colour of the solution changed to the green of $\mathrm{Fe}^{2+}$ in the boiling process, which denotes that Fe has been dissolved out. Fig. 3 shows the linear sweep voltammograms of $\mathrm{FeEw/C}(800)$ catalyst before and after boiling. As can be seen from Fig. 3, the oxygen reduction reaction onset potential of the catalyst is similar before and after boiling, which is about $0.50 \mathrm{~V}$, indicating that the catalytic activity of $\mathrm{FeEw} / \mathrm{C}(800)$ does not diminish by removing Fe. It can be concluded that the Fe and iron oxides are not the active species of the catalyst, but their existence might merely facilitate the formation of active species, which is in accordance with our previous reports ${ }^{17}$.

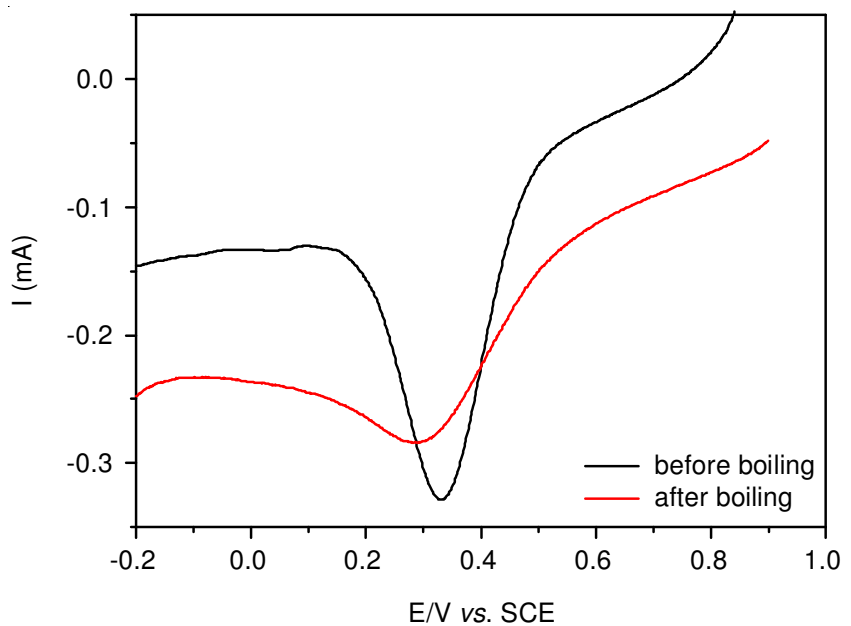

Fig. 3. LSV curves of $\mathrm{FeEw} / \mathrm{C}(800)$ catalyst before and after boiling in 0.5 $\mathrm{M} \mathrm{H}_{2} \mathrm{SO}_{4}$ solution for $1 \mathrm{~h}$, scanning rate: $5 \mathrm{mV} / \mathrm{s}$

Electrocatalytic behaviour of oxygen reduction: Fig. 4 displays the electrocatalytic activity of all the prepared samples. The onset potential was used as the most important parameter to evaluate the catalytic activity for oxygen reduction reaction. It is observed that the $\mathrm{Fe} / \mathrm{C}(800)$ and $\mathrm{FeEw}(800)$ have little oxygen reduction reaction catalytic activity, but the onset potential for the $\mathrm{Ew} / \mathrm{C}(800)$ is $+0.5 \mathrm{~V}$ ( $v s$. SCE). It can be seen that the nitrogen source plays a critical role in the oxygen reduction reaction activity and may be the essential part of the electrocatalytically active sites. In addition, the carbon support has also played a key role in obtaining highly active oxygen reduction reaction catalyst. However, the FeEw/C (800) exhibits more active to the oxygen reduction reaction than the Ew/ C(800) catalyst without adding Fe element, combined with a stronger reduction peak and an oxygen reduction reaction onset potential at $+0.55 \mathrm{~V}$ (vs. SCE). Thus, we concluded that the metal $\mathrm{Fe}$ was not a prerequisite for forming the oxygen reduction reaction-active sites, but it may create a condition for promoting the oxygen reduction reaction activity.

Stability and methanol-tolerant behaviour of the catalyst: Even though the catalysts of Ew/C(800) and FeEw/C(800) showed the excellent catalytic activity for the oxygen reduction reaction, it was vital that further studies on the methanol-tolerant performance and long-term stability should be performed. Fig. 5 shows the stability of Ew/C(800) and FeEw/C(800), which was measured by $\mathrm{CV}$ in $0.5 \mathrm{M} \mathrm{H}_{2} \mathrm{SO}_{4}$ solution. Before

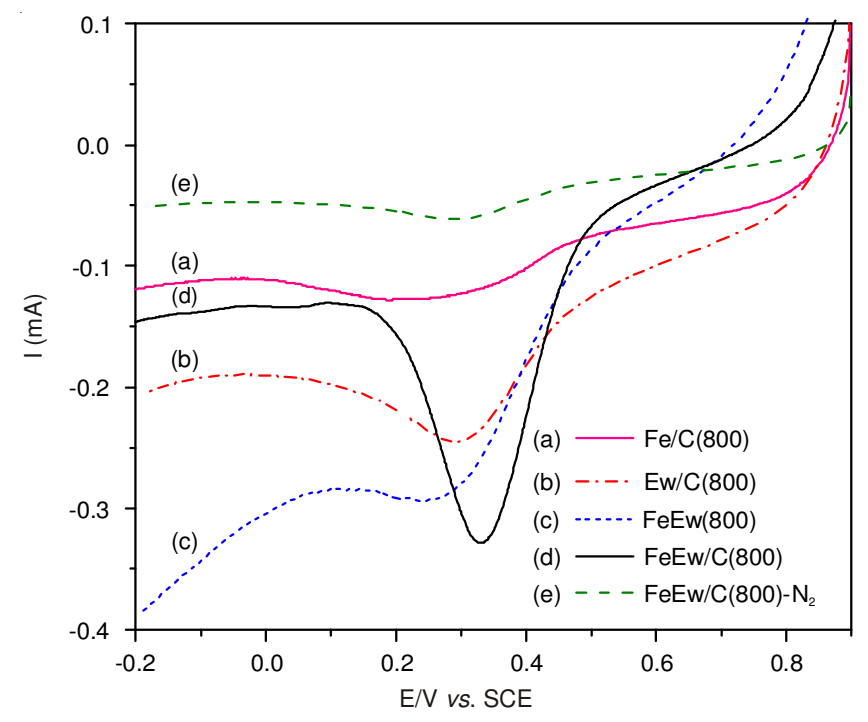

Fig. 4. Linear sweep voltammograms of catalysts (a) Fe/C(800), (b) Ew/ $\mathrm{C}(800)$, (c) $\mathrm{FeEw}(800)$ and (d) $\mathrm{FeEw} / \mathrm{C}(800)$ in $0.5 \mathrm{M} \mathrm{H}_{2} \mathrm{SO}_{4}$ solution saturated by oxygen and (e) FeEw/C(800) in $0.5 \mathrm{M} \mathrm{H}_{2} \mathrm{SO}_{4}$ solution saturated by nitrogen, scanning rate: $5 \mathrm{mV} / \mathrm{s}$

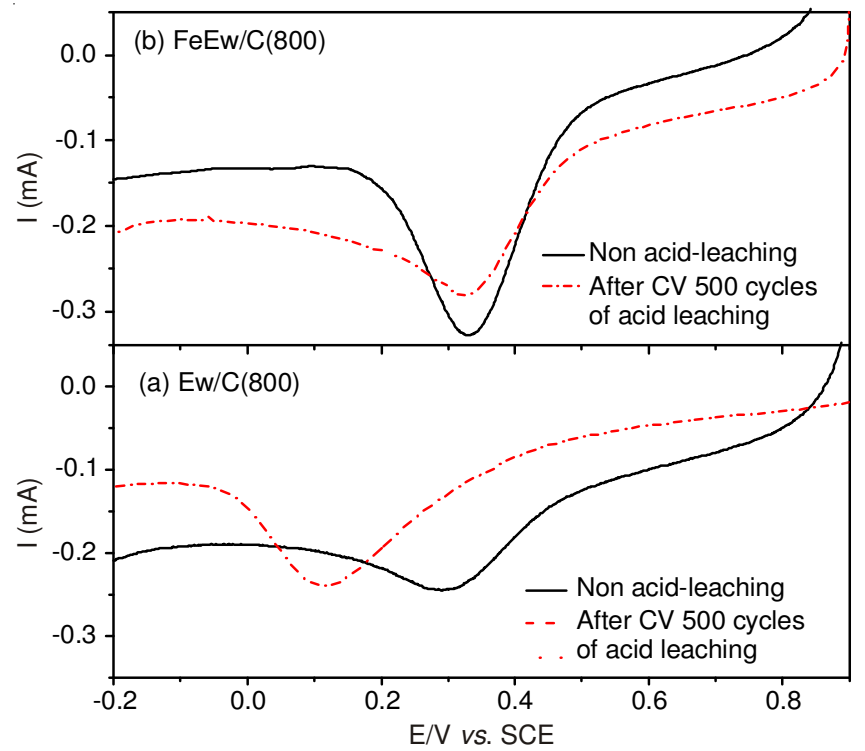

Fig. 5. LSV curves of (a) Ew/C(800) and (b) FeEw/C(800) in $0.5 \mathrm{M} \mathrm{H}_{2} \mathrm{SO}_{4}$ solution saturated by oxygen after continuous potential sweeping 500 cycles in $0.5 \mathrm{M} \mathrm{H}_{2} \mathrm{SO}_{4}$ solution saturated by nitrogen, scanning rate: $50 \mathrm{mV} / \mathrm{s}$

the testing, the two catalysts have undergone 500-cyclic sweeping in $0.5 \mathrm{M} \mathrm{H}_{2} \mathrm{SO}_{4}$ solution saturated by nitrogen at $50 \mathrm{mV} / \mathrm{s}$. The onset potential of Ew/C (800) catalyst has changed from 0.50 to $0.32 \mathrm{~V}$ in Fig. 5a. It can be known that acid leaching might lead to a remarkable decrease in the oxygen reduction reaction activity, which could be due to the loss of metal Fe and the breakage of several oxygen reduction reaction-active species. As shown in Fig. 5b, when compared with the Ew/C (800), the onset potential of the FeEw/C (800) catalyst has not almost been changed. It implies that the stability of the FeEw/C(800) is much better than the Ew/C (800) in acid media. However, it must be pointed out that the metal Fe could facilitate the formation of the oxygen reduction reaction active sites, but also play an important role in their maintenance. In other words, it has protected the active sites from decomposition in an acidic solution. 
The methanol-tolerant properties of Ew/C(800) and FeEw/ $\mathrm{C}(800)$ were also tested in $\mathrm{O}_{2}$-saturated $0.5 \mathrm{M} \mathrm{H}_{2} \mathrm{SO}_{4}$ with $1 \mathrm{M}$ methanol before and after they were undergone the cyclic sweeping for 500 cycles (Fig. 6). It can be found that the methanol oxidation reaction is not observed in the negative and positive potential scanning on the basis of the existence of methanol. Because of methanol oxidation potential is positive and anodic polarization is strong, which have made the methanol oxidation overpotential enhance on the both catalysts. Thus, the catalysts were used for methanol oxidation, but the oxygen reduction reaction activity of Ew/C(800) and FeEw/C(800) catalyst had not been affected obviously. These results indicate that both $\mathrm{Ew} / \mathrm{C}(800)$ and $\mathrm{FeEw} / \mathrm{C}(800)$ have good tolerance to methanol.

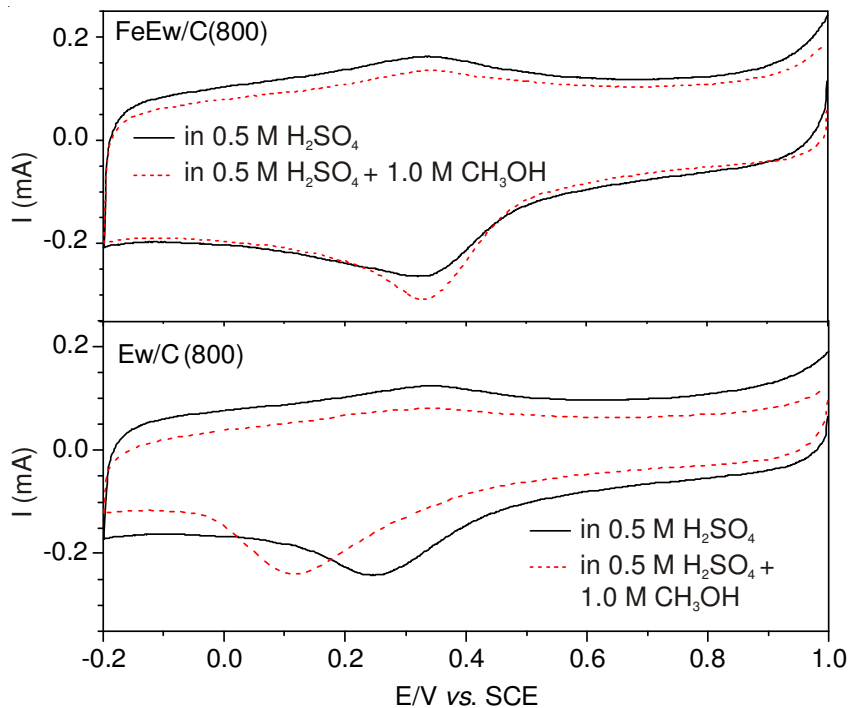

Fig. 6. Cyclic voltammograms of Ew/C(800) and $\mathrm{FeEw} / \mathrm{C}(800)$ in $0.5 \mathrm{M}$ $\mathrm{H}_{2} \mathrm{SO}_{4}$ solution and in $0.5 \mathrm{M} \mathrm{H}_{2} \mathrm{SO}_{4}$ solution containing $1.0 \mathrm{M}$ methanol saturated by oxygen respectively after continuous potential sweeping 5000 cycles in $0.5 \mathrm{M} \mathrm{H}_{2} \mathrm{SO}_{4}$ solution saturated by nitrogen, scanning rate: $50 \mathrm{mV} / \mathrm{s}$

\section{Conclusion}

In summary, compared to Ew/C(800) catalyst, FeEw/C(800) catalyst containing metal elemental $\mathrm{Fe}$ has significant improvement in the oxygen reduction reaction catalytic activity and stability and both performed well in methanol-tolerant performance. The iron oxides are not the active sites of the FeEw/C catalyst to oxygen reduction reaction. However, the existence of Fe facilitates the formation of active sites of the catalyst. It could be concluded that the catalyst FeEw/C (800) may be a promising substitute for the commercial Pt/C catalyst. Some matters including oxygen reduction reaction mechanism and internal pore size development should be intensively studied in the near future.

\section{ACKNOWLEDGEMENTS}

This work was supported by the Fundamental Research Funds for the Central Universities (Project No. CDJXS12220002) and National Undergraduate Innovation Training Project (Project No.1110611046) and Natural Science Fund of China (Project No. 21273292).

\section{REFERENCES}

1. X.Y. Yuan, X. Zeng, H.J. Zhang, Z.F. Ma and C.Y. Wang, J. Am. Chem. Soc., 132, 1754 (2010).

2. J.Y. Choi, D. Higgins and Z.W. Chen, J. Electrochem. Soc. B, 159, B87 (2012).

3. G.Q. Lu and C.Y. Wang. J. Power Sources, 144, 141 (2005).

4. C.W.B. Bezerra, L. Zhang, K.C. Lee, H.S. Liu, A.L.B. Marques, E.P. Marques, H.J. Wang and J.J. Zhang, Electrochim. Acta, 53, 4937 (2008).

5. R. Bashyam and P. Zelenay, Nature, 443, 63 (2006).

6. L. Zhang, J.J. Zhang, D.P. Wilkinson and H.J. Wang, J. Power Sources, 156, 171 (2006).

7. Z.X. Liang, H.Y. Song and S.J. Liao, J. Phys. Chem. C, 115, 2604 (2011).

8. S.C. Thomas, X. Ren, S. Gottesfeld and P. Zelenay, Electrochem. Acta, 47, 3741 (2002).

9. J. Maruyama and I. Abe, Chem. Mater, 18, 1303 (2006).

10. C.Z. Guo, C.G. Chen and Z.L. Luo, J. Power Sources, 245, 841 (2014).

11. J. Maruyama and I. Abe, J. Electrochem. Soc. B, 154, B297 (2007).

12. J. Maruyama, N. Fukui, M. Kawaguchi and I. Abe, J. Power Sources, 182, 489 (2008).

13. C.Z. Guo, C.G. Chen and Z.L. Luo, Int. J. Electrochem. Sci., 8, 8940 (2013).

14. P.B. Xi, Z.X. Liang and S.J. Liao, Int. J. Hydrogen Energy, 37, 4606 (2012).

15. Z.X. Liang, H.Y. Song and S.J. Liao, J. Phys. Chem. C, 115, 2604 (2011).

16. Q. Wang, Z.Y. Zhou, D.J. Chen, J.L. Lin, F.S. Ke, G.L. Xu and S.G. Sun, Sci. China B: Chem., 53, 2057 (2010).

17. Y.J. Si, C.G. Chen, W. Yin and H. Cai, Chin. Chem. Lett., 21, 983 (2010). 